\title{
The Tribological Property and Microstructure of Ni-Ti Coating Prepared by Electrodeposition and Heat Treatment
}

\author{
Chufeng Sun, ${ }^{1,2}$ Yanbin Wang, ${ }^{1}$ Qiong Su, ${ }^{1}$ Zhiguang Guo, ${ }^{2}$ and Lei Shi ${ }^{2}$ \\ ${ }^{1}$ College of Chemical Engineering, Northwest University for Nationalities, Lanzhou 730030, China \\ ${ }^{2}$ State Key Laboratory of Solid Lubrication, Lanzhou Institute of Chemical Physics, Chinese Academy of Sciences, \\ Lanzhou 730000, China
}

Correspondence should be addressed to Lei Shi; leishi@licp.cas.cn

Received 13 November 2015; Accepted 24 January 2016

Academic Editor: Somchai Thongtem

Copyright (c) 2016 Chufeng Sun et al. This is an open access article distributed under the Creative Commons Attribution License, which permits unrestricted use, distribution, and reproduction in any medium, provided the original work is properly cited.

\begin{abstract}
$\mathrm{Ni}$-Ti coatings were fabricated by the electrodeposition in a Ni plating bath containing Ti power and heat treatment in nitrogen atmosphere. The surface morphology and microstructure of the Ni-Ti coating before and after heat treatment were analyzed by means of scanning electron microscopy and X-ray diffraction. The friction and wear behaviors of two different coatings were evaluated on a ball-on-disk UMT-2MT test rig. It was found that the phase structure of Ni-Ti coating heated in nitrogen was much different from that of the as-deposited $\mathrm{Ni}$-Ti coating. Namely, the new intermetallic compounds, including $\mathrm{Ni}_{3} \mathrm{Ti}_{\mathrm{i}} \mathrm{NiTi}^{\mathrm{T}}$, and $\mathrm{NiTi}_{2}$, and TiN were detected in the coating after heat treatment by the XRD analysis and contributed to greatly increasing the hardness and tribological property of the Ni-Ti coating, owing to the strengthening effect of the hard intermetallic compounds and TiN phase. At the same time, a small amount of intermetallic compounds and TiN was transferred from the composite coating to the rubbing surface of the counterpart steel ball during the sliding, which also contributed to decreasing the friction coefficient and increasing the wear resistance.
\end{abstract}

\section{Introduction}

$\mathrm{Ni}$-Ti alloys or coatings usually have various special properties such as biocompatibility $[1,2]$, shape memory effect $[3,4]$, good wear resistance, and corrosion resistance [57]. This is why Ni-Ti alloys or coatings have been finding increased application in the fields of biomedical technology, electronic industries, aerospace, automobile, and so forth. $\mathrm{Ni}-\mathrm{Ti}$ alloys or composites have been fabricated by various techniques and methods, such as spraying $[8,9]$, magnetron sputtering [10, 11], and powder metallurgy [12-14]. Among those methods, electrodeposition is of particular significance as a technique for producing various composite coatings at a normal pressure, ambient temperature, low cost, and high deposition rate. Such a significance of electrodeposition could not be underestimated, since it is feasible to prepare metal-particulates doped metal-matrix composite coatings such as $\mathrm{Ni}-\mathrm{Ti}, \mathrm{Ni}-\mathrm{Al}$, and $\mathrm{Ni}-\mathrm{Cr}$, making use of the in situ codeposition of the metallic particles in the electrodeposition process [15-17]. By means of heat treatment of the asdeposited metal-matrix/metal particle composite coating, some new compounds are formed which, needless to say, usually would be difficult or impossible to produce using conventional electrodeposition methods.

$\mathrm{Ni}$-Ti coating prepared by the electrodeposition in a nickel plating bath containing Ti powers has been reported by Budniok's group [15, 16], Hasannaeimi et al. [18], and Zhao et al. [19], and so forth. The intermetallic compounds can be formed in Ni-matrix composites via heat treatment of electrodeposited Ni-Ti coatings. With a view to the correlation among the structures and performances of the composite materials, it could be practicable by heat treatment to endow $\mathrm{Ni}$ - $\mathrm{Ti}$ composite coating with special properties different from properties of the electrodeposited Ni-Ti coating, because some intermetalic compounds possess high microhardness and good antifriction and wear resistance. Unfortunately, most of the reports about electrodeposited $\mathrm{Ni}-\mathrm{Ti}$ coating are focusing on the effect of the preparation 
parameter, for example, metal powder amount in the bath and deposition current density, on the chemical composition [18], and structure and corrosion properties of the coatings [19], and so far little work has been reported on the tribological properties of Ni-Ti coatings via electrodeposition and heat treatment. The as-deposited Ni-Ti coating was heat-treated in pure $\mathrm{N}_{2}$ atmosphere, which was aiming at increasing the mechanical strength of the coating by the generation of $\mathrm{Ni}$ $\mathrm{Ti}$ intermetallic compounds and $\mathrm{TiN}$ with good chemical stability, high microhardness, and good wear resistance. The surface morphologies, structures, and hardness and tribological properties of Ni-Ti coatings before and after the thermal treatment were comparatively investigated.

\section{Materials and Methods}

The plating bath is composed of $200 \mathrm{~g} \cdot \mathrm{L}^{-1} \mathrm{NiSO}_{4}, 35 \mathrm{~g} \cdot \mathrm{L}^{-1}$ $\mathrm{NiCl}_{2}, 30 \mathrm{~g} \cdot \mathrm{L}^{-1} \mathrm{Na}_{3} \mathrm{C}_{6} \mathrm{H}_{5} \mathrm{O}_{7}, 30 \mathrm{~g} \cdot \mathrm{L}^{-1} \mathrm{H}_{3} \mathrm{BO}_{3}$, and $2 \mathrm{~g} \cdot \mathrm{L}^{-1} \mathrm{Ti}$ powders. Analytical reagents and distilled water were used to prepare the electrodeposition solution. The $\mathrm{pH}$ value of the solution is about $3.8 \pm 0.1$ and the electrodeposition time was $30 \mathrm{~min}$. The Ti powders (diameter of grains $\sim 20 \mu \mathrm{m}$, purity 99.9\%) were dispersed in the electrolyte before plating. The electrodeposition was performed on a model 273A potentiostat/galvanostat device (EG\&G Princeton Applied Research) at $45^{\circ} \mathrm{C}$ and a current density of $50 \mathrm{~mA} \cdot \mathrm{cm}^{-2}$.

During the electrodeposition process, the bath was stirred by a magnetic stirrer at a stirring rate of $150 \mathrm{rpm}$ to ensure a homogeneous suspension and facilitate transportation of the Ti suspension towards the substrate. A platinum mesh of $40 \times 40 \mathrm{~mm}^{2}$ was used as the anode and a saturated calomel electrode (SCE) was used as the reference electrode. A 1Cr18Ni9Ti steel plate of a size $10 \mathrm{~mm} \times 10 \mathrm{~mm} \times 1 \mathrm{~mm}$ and a surface roughness less than $0.05 \mu \mathrm{m}$ were used as the cathode substrate. The steel plate was sequentially ultrasonically cleaned in ethanol, acetone, and distilled water for $10 \mathrm{~min}$, activated in a mixture of $\mathrm{HCl}$ and $\mathrm{H}_{2} \mathrm{SO}_{4}$ for $30 \mathrm{~s}$, washed in distilled water, and then immersed immediately in the plating bath to deposit Ni-Ti coating.

The as-deposited Ni-Ti coating with the thickness of about $110 \pm 10 \mu \mathrm{m}$ was heated at $850^{\circ} \mathrm{C}$ for $20 \mathrm{~h}$ in pure nitrogen atmosphere using a muffle furnace with the heating rate of $5^{\circ} \mathrm{C} / \mathrm{min}$. The morphologies of the coatings were observed using a scanning electron microscope (JEOL JSM$5600 \mathrm{LV})$. The phase structures of the coatings were analyzed using an X-ray diffractometer (XRD, Philips $\mathrm{X}^{\prime}$ PertMRD). The hardness of the coatings was measured on a Vickers' microhardness instrument at a load of $50 \mathrm{~g}$ for $5 \mathrm{~s}$. Five measurements were processed on each sample and the results were averaged. Since the measurement of hardness is always influenced by the substrate, the Jönsson and Hogmark method [20] was used to dissociate the contributions of the substrate and coating of measured hardness. The deviation of the average hardness is less than $4 \%$. The tribological properties of the coatings reciprocally sliding against SAE52100 steel ball ( $3 \mathrm{~mm}$ ) were tested on a UMT-2MT test rig (see Figure 1) in a ball-on-disk configuration. The amplitude of the sliding was $5 \mathrm{~mm}$, a normal load was $0.5 \sim 4.0 \mathrm{~N}$, and a frequency was $3.0 \mathrm{~Hz}$. All the tribological tests were performed under

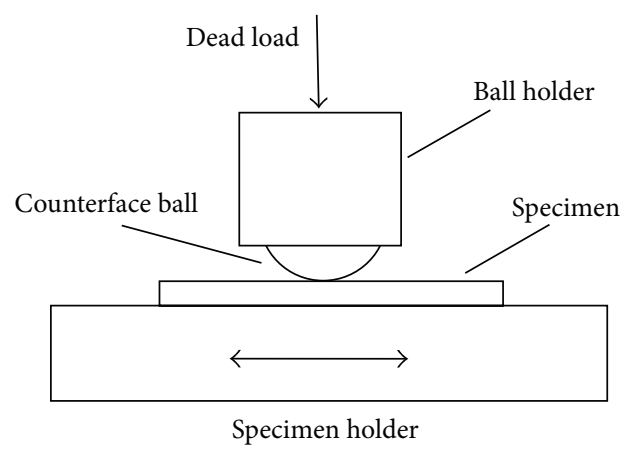

FIGURE 1: Diagrammatic sketch of the friction couple contact.

dry friction condition at room temperature and in ambient air. The friction coefficient was automatically continuously recorded during the test.

\section{Results and Discussion}

3.1. Structures and Morphological Characterizations of $\mathrm{Ni}$ $\mathrm{Ti}$ Coatings. Figure 2 shows the XRD patterns of the asdeposited $\mathrm{Ni}$-Ti coatings before and after heat treatment. It is seen that the as-deposited Ni-Ti coating is characterized by two-phase structure, that is, the nickel and titanium (Figure 2(a)). Namely, the XRD pattern of these coatings confirmed presence of the metal particles embedded into a nickel crystalline matrix. This also confirms that crystalline solid particles of Ti could be embedded into the Ni matrix during the electrodeposition. The Ti phase has a hexagonal structure and the Ni has a cubic structure. After heat treatment in $\mathrm{N}_{2}$ atmosphere, the coatings consist of $\mathrm{Ni}_{3} \mathrm{Ti}$ phase with some minor phases of $\mathrm{NiTi}, \mathrm{TiN}$, and $\mathrm{NiTi}_{2}$ and a sporadic phase of $\mathrm{Ni}$ (Figure 2(b)). $\mathrm{N}_{2}$ gas reacts with Ti particles on the coating surface and simultaneously permeate through pores to react with $\mathrm{Ti}$ particles inside the coating to product $\mathrm{TiN}$ phase under $\mathrm{N}_{2}$ atmosphere and high temperature. In other words, $\mathrm{Ni}$ and $\mathrm{Ti}$ in the as-deposited coatings almost transform into Ni-Ti intermetallic compounds and TiN during the heat treatment process.

The electrodeposition mechanism of Ni-Ti coating can be explained by the adsorption of $\mathrm{Ni}$ ions on the $\mathrm{Ti}$ particles surface. $\mathrm{Ni}^{2+}$ ions, which partly lack the hydration wrapping, can be electrochemically active and liable to move towards the cathode. Because of the electrical conductivity of metal $\mathrm{Ti}$ particles, $\mathrm{Ni}$ experiences transition reaction and is deposited both on the surface of the subtrate and on Ti particles, which allows the generation of the composite coating structure $[16$, $18,21]$.

Figure 3 shows the SEM morphologies of the Ni-Ti coating before and after the heat treatment. It is seen that asdeposited Ni-Ti coating has a particulate-like structure and granular morphology (Figure 3(a)), which indicates that the codeposited Ti particulates were uniformly distributed in the $\mathrm{Ni}$ matrix of the coating. It was also found that the presence of metal particles embedded into the nickel matrix distinctly enlarge the real surface of the coatings. This is because the growth becomes more $3 \mathrm{D}$ in character leading to dendrites 


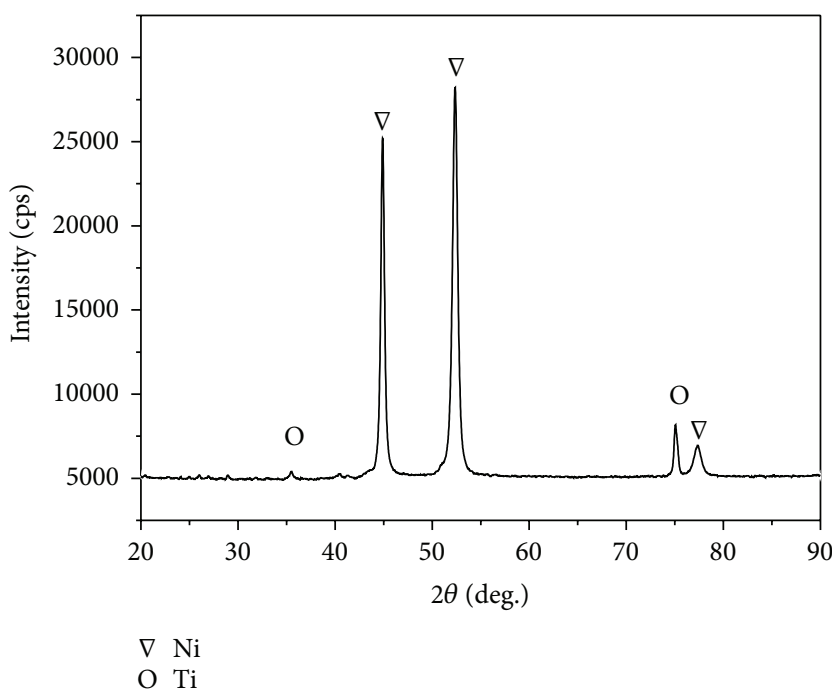

(a)

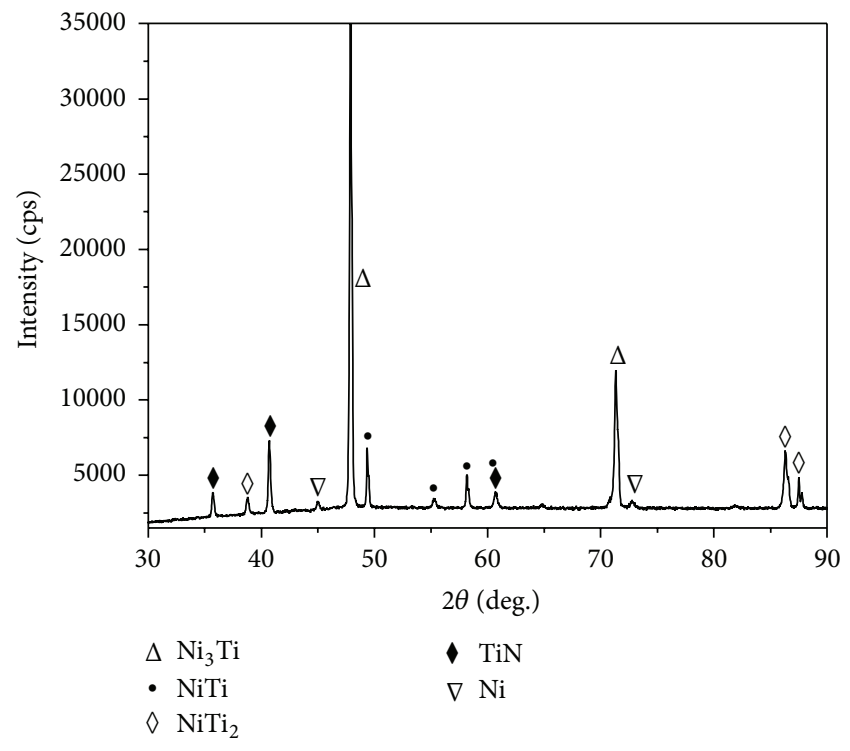

(b)

FiguRE 2: XRD patterns of Ni-Ti coatings (a) before and (b) after the heat treatment.

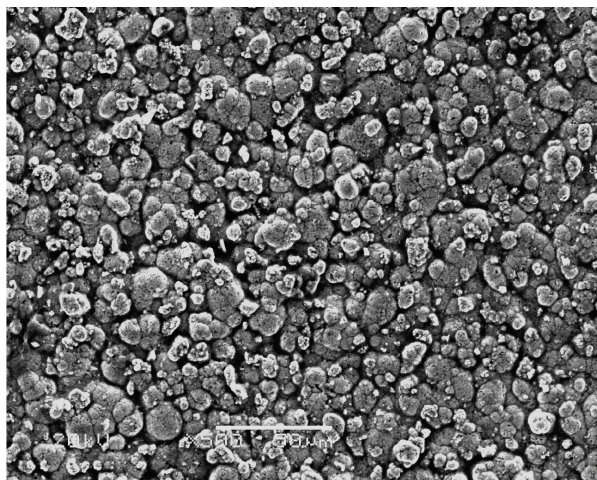

(a)

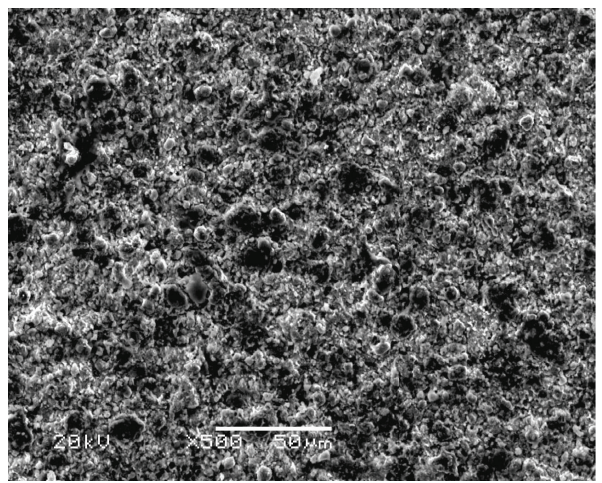

(b)

FIGURE 3: SEM micrographs of Ni-Ti coatings before heat treatment (a) and after heat treatment (b) under the same magnification (zoom in $\times 500)$.

embedded into the layer. It could be observed that $\mathrm{Ni}+\mathrm{Ti}$ coatings morphology clearly changes after heat treatment for $20 \mathrm{~h}$ (Figure 3). Namely, the heat treatment influenced the surface development of the layers obtained. This is a result of total chemical reaction between $\mathrm{Ni}, \mathrm{Ti}$, and $\mathrm{N}_{2}$ which leads to a homogenization of the surface. The surface of Ni-Ti composite coating after the heat treatment has much more flat and finer particles in appearance than that of as-deposited coating (Figure 3(b)). It could be rational to suppose that Newly generated $\mathrm{Ni}$-Ti intermetallic compounds could uniformly distribute in the coatings. Because $\mathrm{N}_{2}$ cannot completely diffuse into the entire coating, the content of TiN near the outer surface is predicted to be higher than that of TiN inside the coating. The hard intermetallic compounds and a small amount of TiN may contribute to increasing the mechanical and tribological properties of the composite coatings.
3.2. Tribological Properties of $\mathrm{Ni}$-Ti Coatings. The production of the intermetallic compounds and a small amount of TiN phases led to a significant increase in the surface microhardness of the composite coating. Namely, the microhardness of the coating after the heat treatment is as high as about $395 \mathrm{Hv}$, and that of the coating before the heat treatment is $198 \mathrm{Hv}$. This means the heat treatment nearly doubles the hardness of the Ni-Ti coating. This is connected with the special structure of the composite coating containing a great amount of hard intermetallic compounds, including $\mathrm{Ni}_{3} \mathrm{Ti}, \mathrm{NiTi}$, and $\mathrm{NiTi}_{2}$, and a small amount of TiN.

Figure 4 shows the variation in the friction coefficients of the Ni-Ti coating after the heat treatment with the sliding cycles under the different load. It is seen that the friction coefficients of the composite coating gradually increase with increasing sliding cycles except that the friction coefficient 


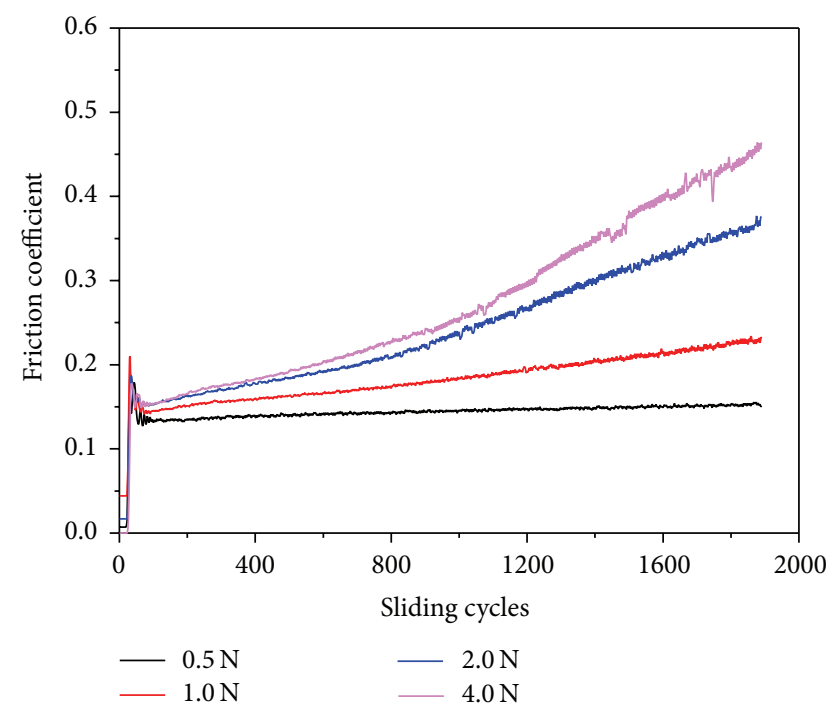

Figure 4: Friction coefficient of Ni-Ti coating after the heat treatment sliding against SAE52100 steel balls as a function of sliding cycles.

at a load of $0.5 \mathrm{~N}$ keeps almost unchanged with increasing sliding cycles. For the hard materials such as intermetallic compounds and TiN, the load is an important factor in the variation of the antifriction and wear resistance. A similar result is observed in other literatures $[22,23]$. At the same time, as listed in Table 1, the average friction coefficient and wear rate of the $\mathrm{Ni}-\mathrm{Ti}$ coating before and after the heat treatment increase with increasing normal load, which is rational, since a larger normal load usually refers to more severe adhesion, scuffing, and cracking of the coatings, which is in accordance with Archard's law [24]. And it is worthy of note that the coating via the heat treatment is helpful for greatly decreasing the friction coefficient and wear rate of the coating, which is attributed to the strengthening effect of the hard NiTi intermetallic compounds and TiN produced during the heating process.

Figure 5 shows the SEM morphologies of the wear scar on the steel ball sliding against the $\mathrm{Ni}$-Ti coating after the heat treatment and $\mathrm{Fe}, \mathrm{Ni}$, and $\mathrm{Ti}$ element distribution thereon. It is seen that a great amount of wear debris was embedded in the worn steel ball surface (see Figure 5(a)), while a small amount of Ni-Ti intermetallic compounds and TiN transferred from the coating was detected on the rubbing surface of the steel ball (see Figures 5(b), 5(c), and 5(d)), similar to what has been reported by Chang et al. [25]. Subsequently, it could be rational to suppose that the Ni-Ti coating after the heat treatment possesses better tribological properties in the presence of hard Ni-Ti intermetallic compounds and TiN with good wear resistance and somewhat solid lubricity $[22,23]$.

The SEM morphologies of the worn surfaces of the Ni-Ti coating after the heat treatment at different loads are shown in Figure 6. It is seen that the wear track of the as-deposited
TABLE 1: Comparison of friction and wear properties of two different coatings at different loads.

\begin{tabular}{lccc}
\hline Coatings & Load $(\mathrm{N})$ & $\begin{array}{c}\text { Average friction } \\
\text { coefficient }\end{array}$ & $\begin{array}{c}\text { Wear rate } \\
\left(\times 10^{-9} \mathrm{~mm}^{3} / \mathrm{Nm}\right)\end{array}$ \\
\hline $\mathrm{a}$ & $0.5 \sim 4.0$ & $0.65 \sim 0.75$ & $3.97 \sim 4.82$ \\
$\mathrm{~b}$ & 0.5 & 0.14 & 1.23 \\
$\mathrm{~b}$ & 1.0 & 0.18 & 1.85 \\
$\mathrm{~b}$ & 2.0 & 0.24 & 2.56 \\
$\mathrm{~b}$ & 4.0 & 0.28 & 3.27 \\
\hline
\end{tabular}

Note: a refers to the as-deposited Ni-Ti coating and $\mathrm{b}$ refers to Ni-Ti coating after the heat treatment.

coating before heat treatment shows signs of severe adhesion, scuffing, and plastic deformation, and some large wear debris is generated thereon (see Figure 6(a)). Different from before heat treatment, the adhesion and scuffing on the worn surface of the coating after heat treatment were significantly abated, though the scuffing and plastic deformation signs are still visible in this case (see Figure 6(b)). Besides, the wear track is shallower and the size of the wear debris obviously decreased on the worn surface of heated coating compared with the asdeposited coating. This could be attributed to the enhanced abrasive action of the wear debris detached from the coating during the sliding. This was rational, since the hard $\mathrm{Ni}-$ $\mathrm{Ti}$ intermetallic compounds and TiN transferred onto the rubbing surface of the counterpart steel ball could serve as the spacers to prevent the rough contact between the coating and the steel ball, which thereby contributed to reduce the wear of the frictional pair. In general, the Ni-Ti coating after the heat treatment showed obvious different worn surface morphologies at different normal loads, which corresponded well with the different friction and wear behaviors thereat.

\section{Conclusions}

It is feasible to prepare $\mathrm{Ni}-\mathrm{Ti}$ coating making use of electrodeposition, by incorporating the to-be-co-deposited Ti powders in the $\mathrm{Ni}$ plating bath and heating the as-deposited $\mathrm{Ni}-\mathrm{Ti}$ coating in $\mathrm{N}_{2}$ atmosphere. Ni-Ti coating after heat treatment possesses much higher hardness than the as-deposited $\mathrm{Ni}$ Ti coating, which is attributed to the strengthening effect of the hard intermetallic compounds, including $\mathrm{Ni}_{3} \mathrm{Ti}, \mathrm{NiTi}$, and $\mathrm{NiTi}_{2}$, and TiN phase produced during the heating process. Namely, the as-deposited Ni-Ti coating has characteristic two-phase structure-hexagonal Ti phase structure and cubic $\mathrm{Ni}$ structure. Different from the as-deposited Ni-Ti coating, the coating after heat treatment is composed of the $\mathrm{Ni}-\mathrm{Ti}$ intermetallic compounds, coexisting TiN generated, and a very small amount of $\mathrm{Ni}$. The newly generated intermetallic compounds and TiN phase with good wear resistance and somewhat solid-lubricity contributed to significantly increasing the tribological properties of $\mathrm{Ni}-\mathrm{Ti}$ coating. The $\mathrm{Ni}-\mathrm{Ti}$ coating has much smaller friction coefficients and wear rate after heat treatment than before heat treatment under the 


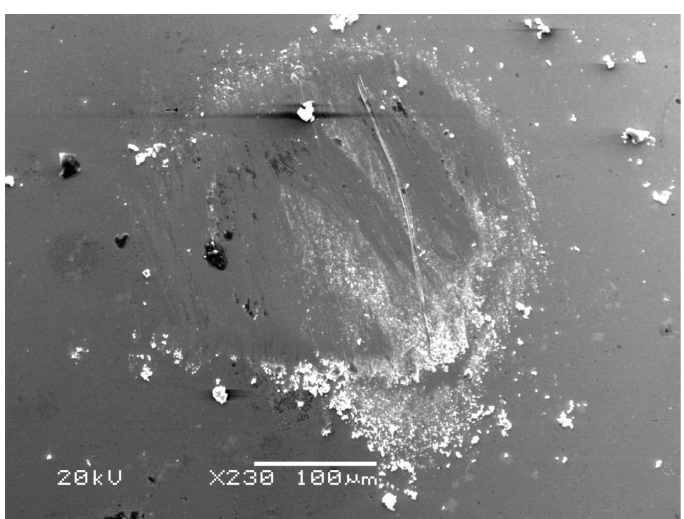

(a)

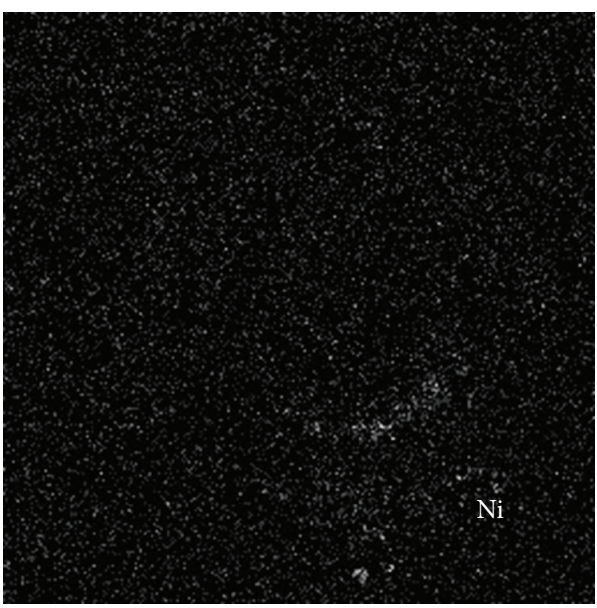

(c)

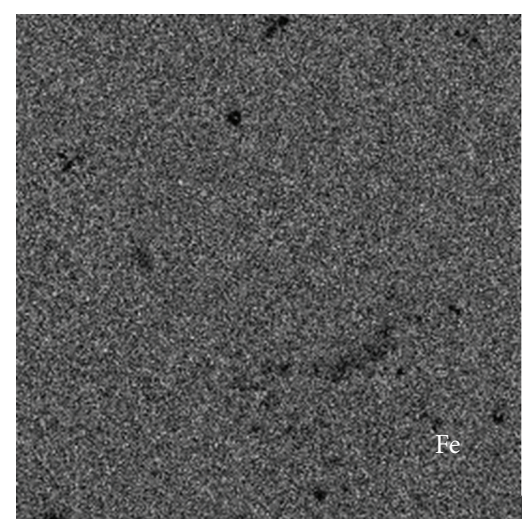

(b)

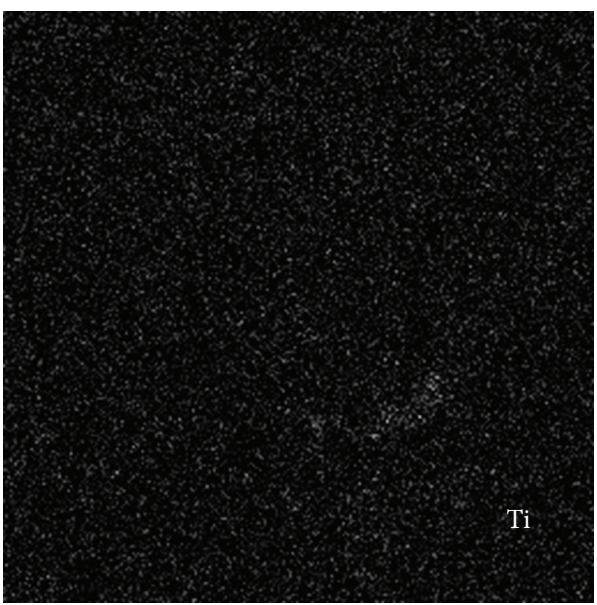

(d)

FIGURE 5: SEM morphologies of (a) wear scar of the steel ball sliding against Ni-Ti coating after the heat treatment at $0.5 \mathrm{~N}$ and $3 \mathrm{~Hz},(\mathrm{~b}) \mathrm{Fe}$ element, (c) Ni element, and (d) Ti element distribution thereon.

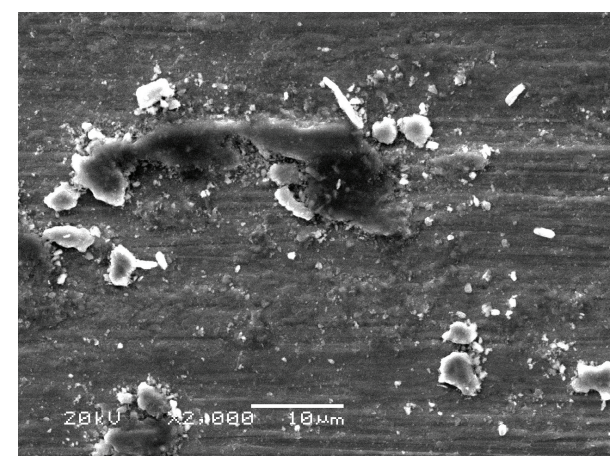

(a)

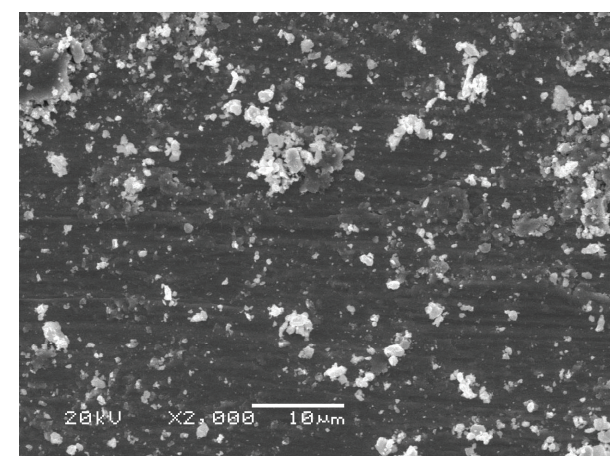

(b)

FIGURE 6: SEM morphologies of the worn surfaces of Ni-Ti coatings (a) before heat treatment and (b) after heat treatment at a load of $4.0 \mathrm{~N}$.

same test conditions, which is attributed to the existence of the hard NiTi intermetallic compounds and TiN and the formation of a transfer layer on the counterpart surface during sliding.

\section{Conflict of Interests}

The authors declare that there is no conflict of interests regarding the publication of this paper. 


\section{Acknowledgments}

The work was supported by the National Natural Science Foundation of China for financial support (Grant no. 51405477) and the Fundamental Research Funds for the Central Universities (31920150002). The authors gratefully acknowledge financial support from China Scholarship Council.

\section{References}

[1] M. H. Elahinia, M. Hashemi, M. Tabesh, and S. B. Bhaduri, "Manufacturing and processing of NiTi implants: a review," Progress in Materials Science, vol. 57, no. 5, pp. 911-946, 2012.

[2] S. M. Toker, D. Canadinc, H. J. Maier, and O. Birer, "Evaluation of passive oxide layer formation-biocompatibility relationship in NiTi shape memory alloys: geometry and body location dependency," Materials Science and Engineering C, vol. 36, no. 1, pp. 118-129, 2014.

[3] T. Zhao, Y. Li, Y. Liu, and X. Zhao, "Nano-hardness, wear resistance and pseudoelasticity of hafnium implanted $\mathrm{NiTi}$ shape memory alloy," Journal of the Mechanical Behavior of Biomedical Materials, vol. 13, pp. 174-184, 2012.

[4] F. M. Braz Fernandes, K. K. Mahesh, R. M. S. Martins, R. J. C. Silva, C. Baehtz, and J. Von Borany, "Simultaneous probing of phase transformations in Ni-Ti thin film shape memory alloy by synchrotron radiation-based X-ray diffraction and electrical resistivity," Materials Characterization, vol. 76, pp. 35-38, 2013.

[5] R. E. McMahon, J. Ma, S. V. Verkhoturov et al., "A comparative study of the cytotoxicity and corrosion resistance of nickeltitanium and titanium-niobium shape memory alloys," Acta Biomaterialia, vol. 8, no. 7, pp. 2863-2870, 2012.

[6] S. A. Fadlallah, N. El-Bagoury, S. M. F. Gad El-Rab, R. A. Ahmed, and G. El-Ousamii, "An overview of NiTi shape memory alloy: corrosion resistance and antibacterial inhibition for dental application," Journal of Alloys and Compounds, vol. 583, pp. 455-464, 2014.

[7] C. Zhang and Z. N. Farhat, "Sliding wear of superelastic TiNi alloy, Wear, vol. 267, no. 1-4, pp. 394-400, 2009.

[8] S. Tria, O. Elkedim, R. Hamzaoui et al., "Deposition and characterization of cold sprayed nanocrystalline NiTi," Powder Technology, vol. 210, no. 2, pp. 181-188, 2011.

[9] J. Stella, E. Schüller, C. Heßing, O. A. Hamed, M. Pohl, and D. Stöver, "Cavitation erosion of plasma-sprayed NiTi coatings," Wear, vol. 260, no. 9-10, pp. 1020-1027, 2006.

[10] S. K. Sharma and S. Mohan, "Effect of chemical treatment on surface characteristics of sputter deposited Ti-rich NiTi shape memory alloy thin-films," Journal of Alloys and Compounds, vol. 592, pp. 170-175, 2014.

[11] L. Zhang, C. Xie, and J. Wu, "Oxidation behavior of sputterdeposited Ti-Ni thin films at elevated temperatures," Materials Characterization, vol. 58, no. 5, pp. 471-478, 2007.

[12] M. M. Verdian, K. Raeissi, M. Salehi, and S. Sabooni, "Characterization and corrosion behavior of $\mathrm{NiTi}-\mathrm{Ti}_{2} \mathrm{Ni}-\mathrm{Ni}_{3} \mathrm{Ti}$ multiphase intermetallics produced by vacuum sintering," Vacuum, vol. 86, no. 1, pp. 91-95, 2011.

[13] G. Tosun, L. Ozler, M. Kaya, and N. Orhan, "A study on microstructure and porosity of NiTi alloy implants produced by SHS," Journal of Alloys and Compounds, vol. 487, no. 1-2, pp. 605-611, 2009.
[14] J. Y. Xiong, Y. C. Li, X. J. Wang, P. D. Hodgson, and C. E. Wen, "Titanium-nickel shape memory alloy foams for bone tissue engineering," Journal of the Mechanical Behavior of Biomedical Materials, vol. 1, no. 3, pp. 269-273, 2008.

[15] I. Napłoszek-Bilnik, A. Budniok, B. Łosiewicz, L. Pająk, and E. Łągiewka, "Electrodeposition of composite Ni-based coatings with the addition of Ti or/and Al particles," Thin Solid Films, vol. 474, no. 1-2, pp. 146-153, 2005.

[16] A. Serek and A. Budniok, "Electrodeposition and thermal treatment of nickel layers containing titanium," Journal of Alloys and Compounds, vol. 352, no. 1-2, pp. 290-295, 2003.

[17] Z. Dong, X. Peng, Y. Guan, L. Li, and F. Wang, "Optimization of composition and structure of electrodeposited Ni-Cr composites for increasing the oxidation resistance," Corrosion Science, vol. 62, pp. 147-152, 2012.

[18] V. Hasannaeimi, T. Shahrabi, and S. Sanjabi, "Fabrication of NiTi layer via co-electrodeposition of nickel and titanium," Surface and Coatings Technology, vol. 210, pp. 10-14, 2012.

[19] Y. Zhao, C. Jiang, Z. Xu, F. Cai, Z. Zhang, and P. Fu, "Microstructure and corrosion behavior of $\mathrm{Ti}$ nanoparticles reinforced $\mathrm{Ni}-\mathrm{Ti}$ composite coatings by electrodeposition," Materials \& Design, vol. 85, pp. 39-46, 2015.

[20] B. Jönsson and S. Hogmark, "Hardness measurements of thin films," Thin Solid Films, vol. 114, no. 3, pp. 257-269, 1984.

[21] J. Panek and A. Budniok, "Production and electrochemical characterization of Ni-based composite coatings containing titanium, vanadium or molybdenum powders," Surface and Coatings Technology, vol. 201, no. 14, pp. 6478-6483, 2007.

[22] M. Abedini, H. M. Ghasemi, and M. N. Ahmadabadi, “Tribological behavior of NiTi alloy against 52100 steel and WC at elevated temperatures," Materials Characterization, vol. 61, no. 7, pp. 689-695, 2010.

[23] E. E. Vera, M. Vite, R. Lewis, E. A. Gallardo, and J. R. LagunaCamacho, "A study of the wear performance of TiN, CrN and WC/C coatings on different steel substrates," Wear, vol. 271, no. 9-10, pp. 2116-2124, 2011.

[24] J. F. Archard, "Elastic deformation and the laws of friction," Proceedings of the Royal Society A: Mathematical, Physical and Engineering Sciences, vol. 243, no. 1233, pp. 190-205, 1957.

[25] C. H. Chang, M. C. Jeng, C. Y. Su, and T. S. Huang, "A study of wear and corrosion resistance of arc-sprayed $\mathrm{Ni}$-Ti composite coatings," Journal of Thermal Spray Technology, vol. 20, no. 6, pp. 1278-1285, 2011. 

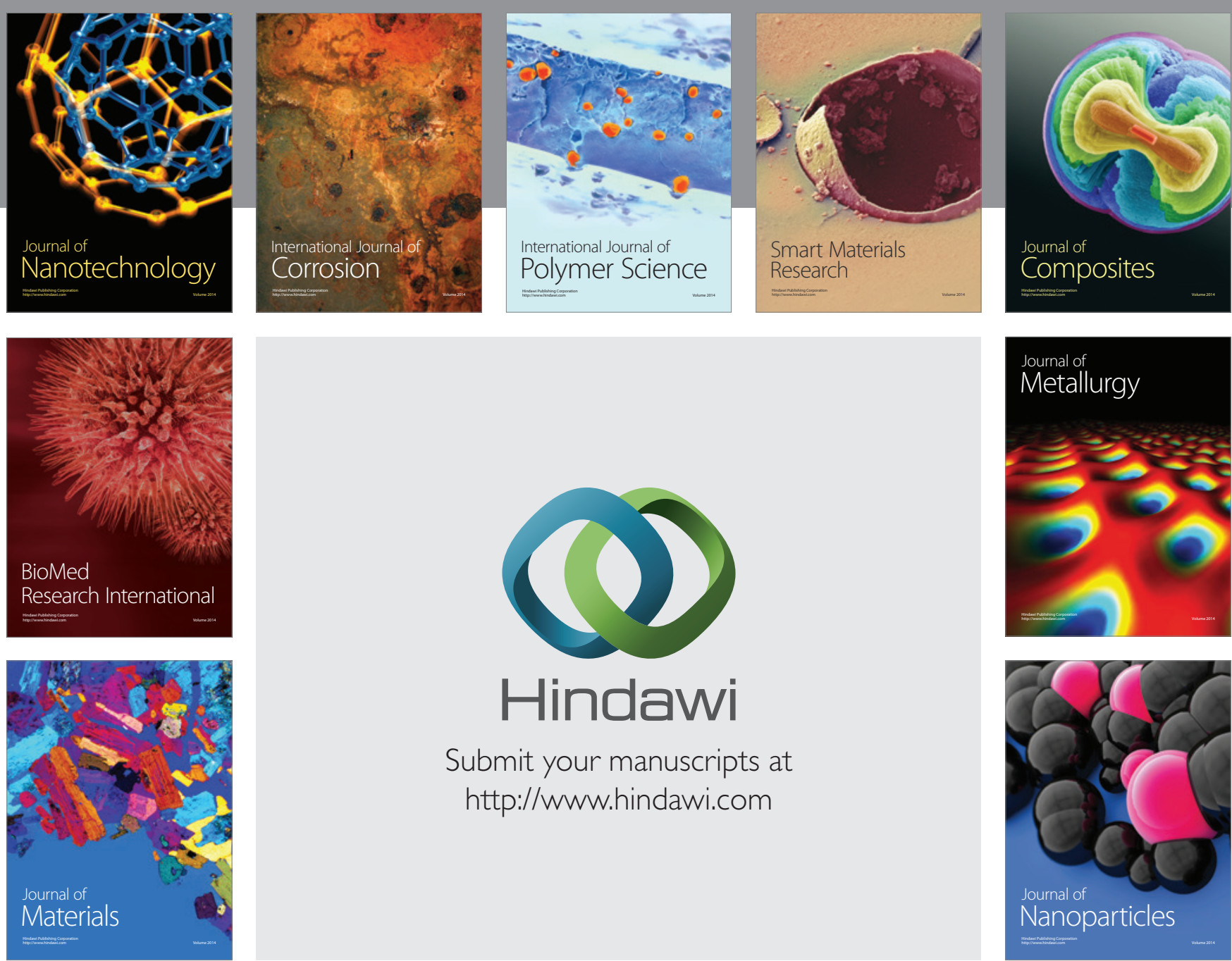

\section{Hindawi}

Submit your manuscripts at

http://www.hindawi.com

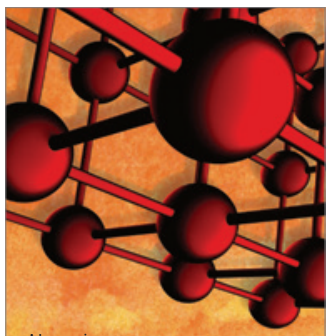

Materials Science and Engineering
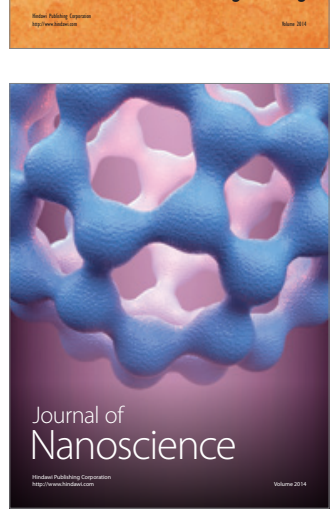
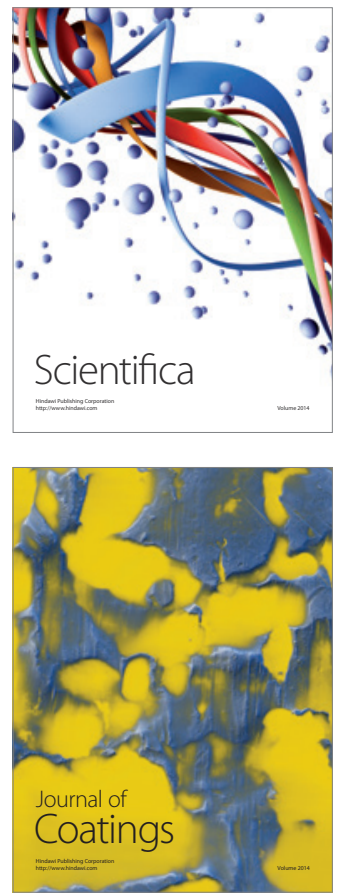
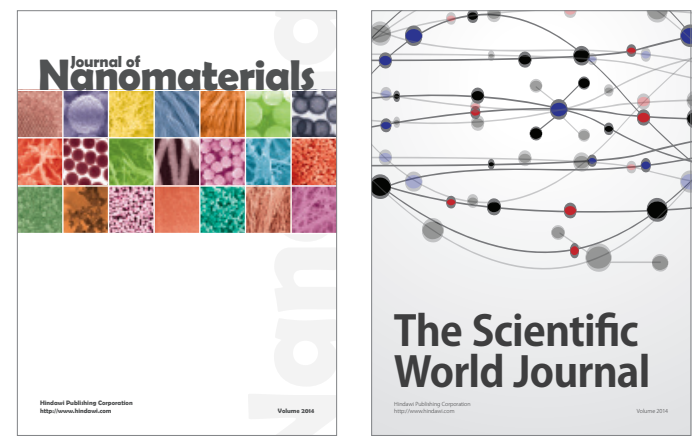

The Scientific World Journal
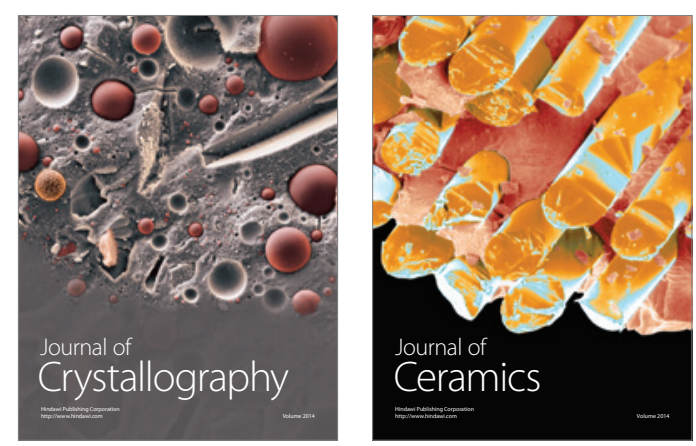
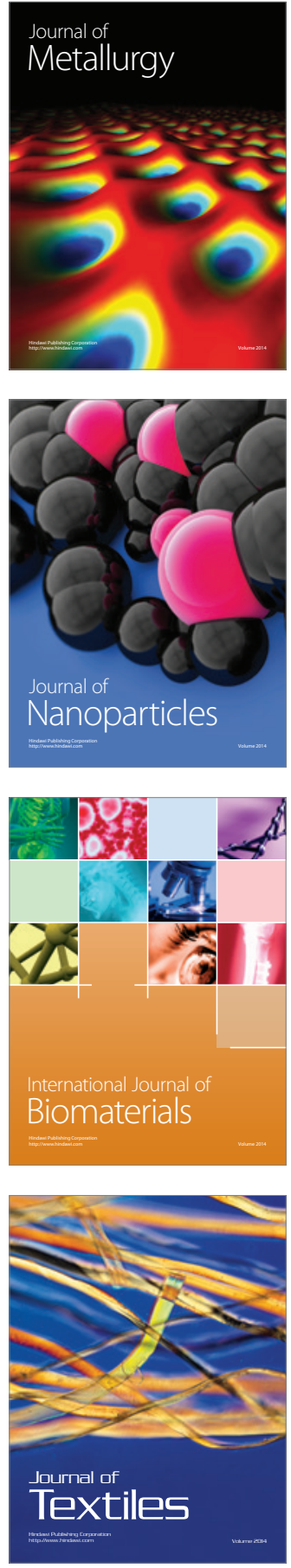